\title{
DETERMINANTES DE LA PRODUCTIVIDAD TOTAL DE FACTORES EN AMÉRICA DEL SUR
}

\section{Andrés M. Gutiérrez Villca}

\section{RESUMEN}

Este estudio identifica los determinantes de la Productividad Total de Factores (PTF) de América del Sur haciendo uso de técnicas econométricas de datos panel con la aproximación de diversos indicadores económicos, institucionales, tecnológicos y sociales. Entre los principales resultados se destacan la fuerte contribución a la PTF de los términos de intercambio, el ahorro, la apertura externa, el salario real, la inversión extranjera. En cuanto al capital humano presentan efectos positivos, pero de magnitud reducida, expresándose en la baja formación y capacitación de los trabajadores. Los entornos institucional y tecnológico, reportan efectos positivos de magnitud reducida. La volatilidad de los términos de intercambio, la informalidad, la desigualdad, la fertilidad, reportan efectos negativos de magnitudes altas. Por país se identifica que las economías que incrementaron sus dotaciones de capital humano y fortalecimiento del entorno institucional, aumentaron su productividad eficientemente, por el contrario, las economías que no presentaron mejoras en dichas áreas fueron rezagando su productividad. En una retrospección histórica 1976 a 2015, la contribución de la PTF al crecimiento económico regional fue marcado preeminentemente por el comportamiento de los términos de intercambio.

Palabras Clave: Productividad Total de Factores, Crecimiento Económico.

DOI: 10.23881/idupbo.019.2-1e 